\title{
ARQUITECTURA, MOBILIARIO Y PROYECTO PEDAGÓGICO: EL PABELLÓN DE LA RESIDENCIA DE SEÑORITAS ESTUDIANTES, 1932-1933
}

\author{
María Villanueva Fernández, Héctor García-Diego Villarías
}

\begin{abstract}
Durante las décadas de1920 y 1930 se hacen más frecuentes las propuestas de arquitectura europeas que plantean una tipología de mueble multifuncional que complementa y configura el espacio arquitectónico. Algunos arquitectos comienzan a diseñar este mobiliario como signo de modernidad y como una nueva estrategia espacial propia de la arquitectura. Entre ellos se encuentra el arquitecto Carlos Arniches quien diseñó el pabellón de la Residencia de Señoritas Estudiantes como un edificio vanguardista adecuado a la modernidad del proyecto pedagógico de la Junta. Esta investigación analiza esta obra, desde la arquitectura hasta el diseño de mobiliario, como factor potenciador del proyecto pedagógico moderno de la Junta para Ampliación de Estudios, y reconstruye el proceso de creación a partir de los documentos encontrados en el Archivo de la Residencia de Señoritas y las revistas de arquitectura de la época.
\end{abstract}

Palabras clave: Mobiliario, Residencia de Señoritas, María de Maeztu, Carlos Arniches Keywords: Furniture, Residencia de Señoritas, María de Maeztu, Carlos Arniches

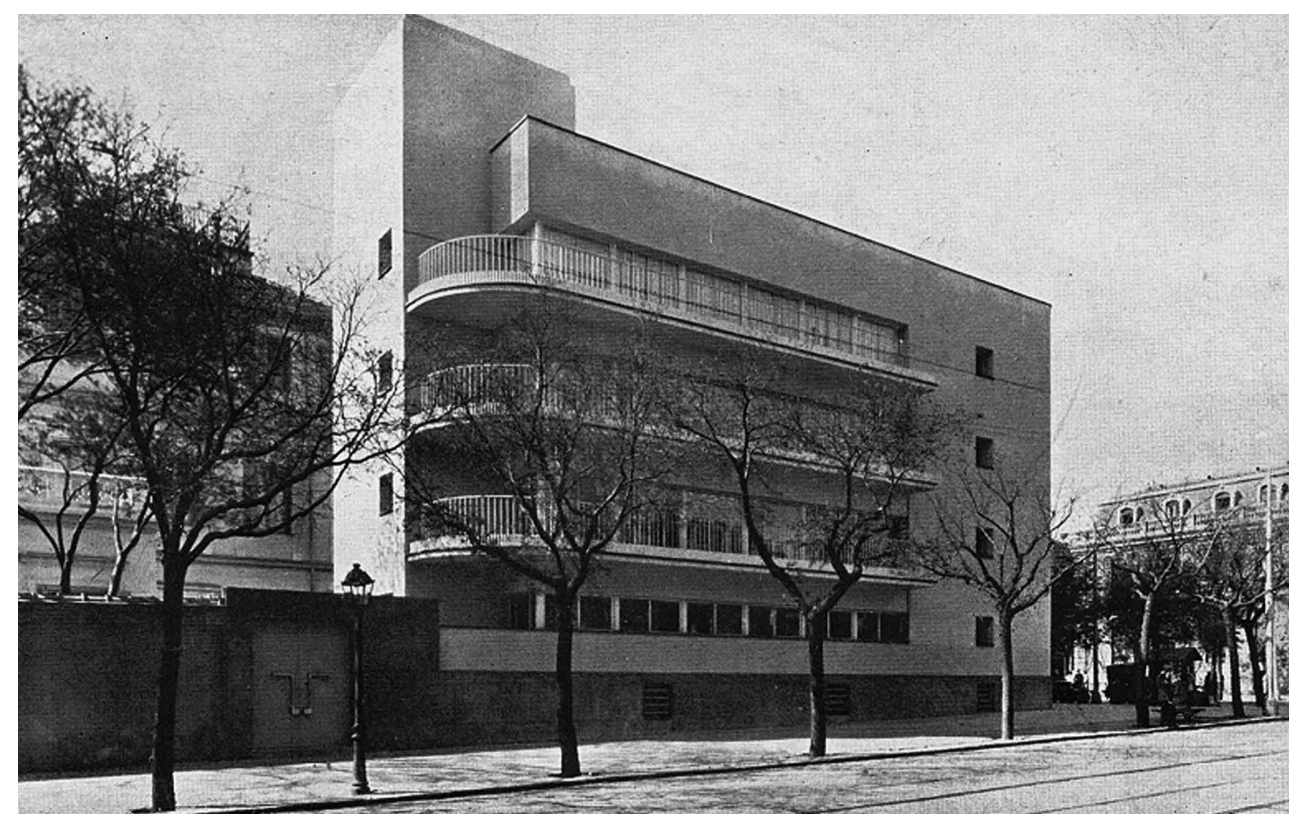

El 7 de Junio de 1932, María de Maeztu, Directora de la Residencia de Señoritas Estudiantes (Fig. 1), escribía una carta ${ }^{1}$ a José Castillejo, Secretario de Junta para Ampliación de Estudios e Investigaciones Científicas ${ }^{2}$-organismo del cual dependía la Residencia. En pocas líneas, el escrito recogía una colección de datos, nombres y voluntades que, sin duda, forman parte de la historia del pabellón de la Residencia de Señoritas.

El motivo principal de la carta era solicitar permiso para llevar a cabo la construcción de un nuevo edificio en la parcela de la calle Fortuny número 53. La creación de un pabellón, principalmente de uso residencial, se había convertido en una necesidad ${ }^{3}$ apremiante a causa del aumento de demanda de plazas producido desde la apertura de la primera Residencia de Señoritas en octubre de 1915. Inicialmente, fue situada en dos hoteles de la calle Fortuny, los números 28 y 30, que la célebre Residencia de Estudiantes había desocupado al trasladarse al nuevo edificio de los Altos del Hipódromo. Pronto la Residencia femenina se vio en la necesidad de ocupar más locales, propiciado por el aumento del número de alumnas admitidas, aunque no el suficiente -tal y como se expresa en la Memoria de los años 1915, 1916 y 1917.
Fig. 1. Fotografía del nuevo pabellón de la Residencia de Señoritas, Madrid, 1933.
1. Correspondencia de María de Maeztu a José Castillejo, 7 de Junio de 1932, Archivo de la Residencia de Señoritas (Fundación José Ortega y Gasset-Gregorio Marañón), 65/8/1. Se agradece al Archivo de la Residencia de Señoritas (Fundación José Ortega y Gasset-Gregorio Marañón), sin el cual no hubiera sido posible realizar esta investigación.

2. También es referenciada como JAE o Junta a lo largo del artículo. Los objetivos de la Junta, expresados en la Memoria 1907-1909, fueron: "provocar una corriente de comunicación científica y pedagógica con el extranjero" y "agrupar en núcleos de trabajo intenso y desinteresado los elementos disponibles del país". Memoria de la Junta para Ampliación de Estudios 1907-1909, p. 4.

3. Memoria de la Junta para Ampliación de Estudios, del 1 de julio de 1932 al 30 de septiembre de 1933, Archivo de la Residencia de Señoritas (Fundación José Ortega y GassetGregorio Marañón). 
4. Para profundizar en la figura de María de Maeztu, hermana de los destacados Ramiro y Gustavo de Maeztu, y en su labor docente se recomiendan los textos siguientes: GAMERO MERINO, Carmela, "Aproximación a la labor pedagógica de María de Maeztu", en Revista Española de Pedagogía, vol. 43 n. 167, Universidad Internacional de La Rioja, 1985. pp. 111 138. PÉREZ-VILLANUEVA TOVAR, Isabel, María de Maeztu. Una mujer en el reformismo educativo español, UNED, Madrid, 1989

5. DIEZ-PASTOR, Concha, Carlos Arniches y Martín Domínguez: arquitectos de la generación del 25, Mairea, Madrid, 2005, p. 141

6. Correspondencia de María de Maeztu a José Castillejo, op. cit., $65 / 8 / 1$.

7. Ídem

8. DE LA CUEVA, Almudena; MÁRQUEZ PADORNO, Margarita, Mujeres en vanguardia: la residencia de señoritas en su centenario (1915-1936), Publicaciones de la Residencia de Estudiantes, Madrid, 2015, p. 311.

9. DIEZ-PASTOR, Concha, op. cit., p. 57.

10. La labor de Carlos Arniches, que duraría casi una década, consistía tanto en la adecuación de los edificios propiedad de la JAE a través de reformas y rehabilitaciones, como en proyectos de nueva planta, ya fuesen ampliaciones parciales 0 edificios completos como el de la Residencia de Señoritas. Entre estas obras se encuentran: el Instituto-Escuela en los Altos del Hipódromo, el Pabellón de Bachillerato, el Parvulario, el Auditórium y la Biblioteca de la Residencia de Estudiantes -realizadas junto a Martín Domínguez, quien sería su compañero profesional y amigo. DIEZ-PASTOR, Concha op. cit., p. 61; LACASA, Luis, Escritos, 1922-1931, Porrúa Turanzas, Madrid, 1976, p. 17.

11. ZULUETA, Carmen de; MORENO, Alicia, Ni convento ni college: La Residencia de Señoritas, Publicaciones de la Residencia de Estudiantes, Consejo Superior de Investigaciones Científicas y Asociación de Amigos de la Residencia de Estudiantes, Madrid, 1993, p. 113.

12. Aunque las obras realizadas durante este periodo son atribuidas en ocasiones a ambos arquitectos, según afirma Concha Diez-Pastor, "todas fueron firmadas exclusivamente por Carlos Arniches salvo dos reformas de 1935 en los aseos de uno de los pabellones, que firmaron conjuntamente". DIEZ-PASTOR, Concha, op. cit., p. 127

13. RAMÍREZ POTES, Francisco, "Arquitectura y pedagogía en el desarrollo de la arquitectura moderna", en Revista Edu cación y Pedagogía, vol. 21, n. 54, Universidad de Antioquia, 2009. pp. 30-65.

14. DIEZ-PASTOR, Concha, op. cit., p. 141.

15. El arquitecto justifica la forma del edificio en $L$ como mecanismo para mantener las distancias necesarias entre el edificio preexistente y la nueva construcción. Memoria del edificio por Carlos Arniches, mayo 1932, Archivo de la Residencia de Señoritas (Fundación José Ortega y GassetGregorio Marañón), 65/2/3, p. 2.
Fue entonces cuando María de Maeztu ${ }^{4}$, directora de la Residencia de Señoritas, al contemplar cómo la Junta desoía sus quejas a causa de la falta de espacio, decidió encargarse personalmente de solucionar el problema ${ }^{5}$. La directora propuso entonces a la Junta financiar la nueva obra con el presupuesto de la propia Residencia ${ }^{6}$ para así poder realizar el proyecto con mayor rapidez, tal y como recogía en la citada $\operatorname{carta}^{7}$, y comenzar a utilizar las instalaciones el 1 de Enero de 1933. Se trataba de la primera obra que se construía ex novo para el centro $^{8}$.

María de Maeztu encargó el proyecto del nuevo pabellón a Carlos Arniches, quien en aquel momento ocupaba el cargo de Arquitecto Director de los edificios de la JAE desde su nombramiento en agosto de $1927^{9}$. Su trabajo consistía en la conservación, reforma y ampliación de la arquitectura propiedad de la Junta ${ }^{10}$. Esta actividad tuvo gran desarrollo durante la República ya que la Residencia, al igual que la JAE, fue favorecida por los nuevos gobiernos a través de sus políticas. Se propiciaba un mayor crecimiento no sólo en lo físico, sino también en aspectos referentes al estilo de vida inculcado en el centro de la calle Fortuny, que iban desde la conducta para la vida cotidiana hasta la elección del mobiliario $^{11}$

La apuesta por la mejora de la educación demandaba una arquitectura a su nivel, por lo que la Junta impulsó la construcción de nuevos edificios. Por un lado, Arniches tuvo la oportunidad de erigir las obras más importantes de su carrera profesional hasta ese momento. Por otro, pudo formar parte, con su arquitectura, de un proyecto de mayor envergadura -iniciado en el siglo anterior por Sanz del Río, tras él, Giner de los Ríos y que en aquel momento la JAE, con José Castillejo como secretario, continuaba desarrollando- incluido en la deseada revolución pedagógica y cultural de la sociedad española de la época.

Las obras que Arniches ${ }^{12}$ realizó para la Junta formaban parte de una operación de vanguardia que trascendía la propia arquitectura, asumiendo un papel esencial dentro del proyecto pedagógico que se pretendía realizar. En este contexto, Arniches pudo realizar un conjunto de edificios que no sólo se encontraban dentro de una modernidad formal, sino que podían ser considerados modernos de concepto por su uso, función, programa y construcción ${ }^{13}$. Entre ellos se encuentra el pabellón de la Residencia de Señoritas Estudiantes.

\section{EL PABELLÓN DE LA RESIDENCIA DE SEÑORITAS ESTUDIANTES}

El proyecto de Arniches, urgía cada vez más como consecuencia de las dificultades derivadas de las obras realizadas a causa de un fuerte tempora ${ }^{14}$. El nuevo edificio debía cumplir una función prioritariamente habitacional que proporcionase la mayor cantidad de dormitorios posible, ya que el resto de estancias -comedores, salones, biblioteca y dependencias comunes- se iban a mantener en el edificio central de Fortuny 53, la 'casa'-como la llamaba María de Maeztu en sus cartas.

El nuevo pabellón se ubicó en la esquina de la calle Miguel Ángel con la calle Francisco Giner de los Ríos -hoy General Martínez Campos-, en el ángulo Noroeste de la propiedad de la JAE donde ya se encontraba la casa de la Residencia de Señoritas. El edificio de Arniches, con azotea aterrazada, tenía cuatro plantas de dormitorios y un sótano con una gran sala, cuartos de instalaciones, lavaderos y espacio para la plancha. Arniches ofreció una detallada descripción de las principales características de su proyecto en la Memoria del edificio de mayo de 1932. En ella explicaba que el edificio, con "forma de escuadra" en planta, era vertebrado por un pasillo central que lo recorría. Los dormitorios se situaban en el lateral del corredor orientado hacia el interior de la parcela y en el lateral situado junto a la calle Miguel Ángel.

De este modo, Arniches conseguía “18,50 m de fachadas al mediodía y a levante, orientación conveniente para dormitorios; $14 \mathrm{~m}$ a poniente y 22,35 al norte" 15 . La fachada norte quedaba desocupada de habitaciones y permanecía abierta a la calle mediante una galería de comunicación acristalada, que daba a un balcón exterior por planta, rematado con un cuarto de circunferencia que recuerda a las arquitecturas europeas de la época. El recorrido 
del pasillo nacía en la entrada principal de la Residencia, donde el espacio era presidido por una original escalera y culminaba en el extremo opuesto con un balcón semicircular sobre el jardín. Los servicios se encontraban "lo más equidistantes posibles de todos los dormitorios: en el chaflán formado por las fachadas S. y E." "16 (Fig. 2).

Los dormitorios fueron diseñados por Arniches para que se adaptasen del mejor modo posible a las necesidades de las residentes. El nuevo pabellón, según explica el arquitecto en la Memoria del edificio, contaba con 40 habitaciones, de las que destacaba especialmente su carácter individual ${ }^{17}$. Esto, posiblemente, era debido a la voluntad de Arniches por adecuar su obra al modelo de formación planteado por la institución para las mujeres, basado en una educación integral en un régimen de "prudente libertad", tal y como lo recoge María de Maeztu en un borrador de una Memoria de la $\mathrm{JAE}^{18}$. Pretendían, en palabras de Virginia Woolf, proporcionar a las residentes 'una habitación propia' ${ }^{19}$ donde poder desarrollar una actividad de formación superior y universitaria.

La oferta formativa, tanto para el cultivo intelectual como físico, era muy amplia: idiomas, clases de cultura general y de las propias asignaturas que constituían los programas académicos, "laboratorios, biblioteca, conferencias, conciertos, excursiones y deportes" ${ }^{20}$. Sin embargo, la formación intelectual no era la única que las muchachas recibieron. En un borrador de una memoria de la JAE María de Maeztu explicaba que el objetivo de la Residencia atañía otros aspectos más allá de los puramente académicos: "La labor de la residencia no se limita a dar a las alumnas una intensa formación intelectual. Intenta ofrecer a las muchachas un ambiente sano, favorable a los ideales morales" ${ }^{21}$. Muchos de ellos aparecían explicados en el Libro Azul que era el reglamento de la Residencia de Señoritas.

Por lo tanto, el nuevo pabellón de Arniches no era estrictamente una residencia, sino que más bien se trataba de un espacio dedicado al estudio y a la formación integral ${ }^{22}$ de las señoritas. El proyecto de Arniches debía no sólo permitir sino también favorecer el desarrollo de aquellos objetivos. No es de extrañar, por tanto, que el arquitecto incluya como parte esencial del proyecto la definición precisa del mobiliario, siguiendo para su realización las ideas tanto de Giner y Cossío - krausistas cuyas tesis seguía ${ }^{23}$ - como las exigencias de María de Maeztu.

En 1882, Giner de los Ríos publicó en el Boletín de la Institución Libre de Enseñanza -de la que era director-, el texto "Local y el mobiliario en la escuela", en donde solicitaba la aplicación de "un criterio de máxima economía, prescindiendo por completo de cualquier gasto innecesario como el derivado de los adornos superfluos" 24 . Además de proponer un tipo de arquitectura sencilla y sin ornamento, consideraba de vital importancia el diseño del mobiliario ${ }^{25}$ dentro del edificio docente. Asimismo, su discípulo Manuel Bartolomé Cossío continuó con el trabajo de su maestro centrándose concretamente en el fin del edifico y las necesidades de los usuarios, en su texto "Notas sobre construcción escolar" 26 .

Tanto María de Maeztu como José Castillejo -y, por tanto, la JAE- trataron de modelar una Residencia que, además de ser una institución avanzada en materia educativa, respondiera a la "libertad de una familia española bien organizada" 27 . Con la intención de inculcar el hábito del trabajo a las estudiantes, las actividades en la Residencia no cesaban desde las ocho de la mañana hasta las once de la noche. Esta organización y orden inculcados por la directora debían ser reflejados en la obra de Arniches a nivel general y, muy especialmente, a nivel particular en los dormitorios y su mobiliario ${ }^{28}$. El mueble debía ser sencillo y responder a los criterios de racionalidad y funcionalidad que propugnaban Giner y Cossío teniendo siempre muy presente el tipo de usuario para el que se había proyectado.

Además de estas cuestiones, Arniches se enfrentaba a un problema de espacio derivado del propio proyecto. Debido al propósito de crear estancias individuales para las residentes, las dimensiones de las habitaciones resultaron reducidas, "aunque no insuficientes" 29 como explicaba el propio arquitecto. El espacio libre del dormitorio era, de media, de 2,90 x 2,90 metros. Esta área se completaba con una franja de 0,70 metros en la que Arniches había con-

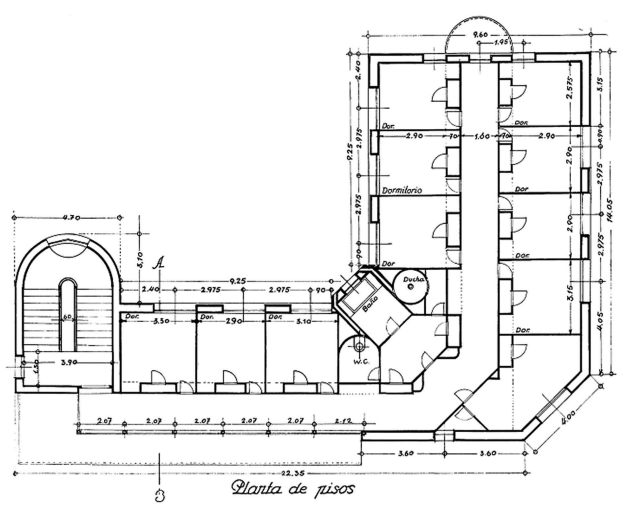

Fig. 2. Planta de la Residencia de Señoritas de Carlos Arniches (1932-1933), publicada en Nuevas Formas, 1935.

16. Ídem.

17. "Los dormitorios individuales son 11 por planta, deduciendo en la planta baja, en el espacio que ocuparían tres, un despacho, inmediato a la entrada, y un salón, en una de las plantas intermedias, un cuarto destinado a la plancha y lavado de pequeña importancia." Memoria del edificio por Carlos Arniches, op. cit., 65/2/3, p. 2.

18. Borrador de Memoria, s/f, Archivo de la Residencia de Señoritas (Fundación José Ortega y Gasset-Gregorio Marañón). CAPEL MARTÍNEZ, Rosa María, "El archivo de la Residencia de Señoritas", Patrimonio en la escuela, en Participación educativa, n. 11, Consejo Escolar del Estado, 2009. pp. 156-161, pp. 157-158.

19. En 1929, Virginia Woolf publicó su famoso ensayo feminista A Room of One's Own (Una habitación propia), basado en las conferencias sobre la mujer en la literatura inglesa en Newnham y Girton, los pioneros colleges femeninos de la Universidad de Cambridge. Según explican De la Cueva y Márquez, "Virginia Wolf cifra en esa habitación el símbolo de la emancipación de la mujer, de la libertad intelectual y personal (...)". DE LA CUEVA, Almudena; MÁRQUEZ PADORNO, Margarita. (Ed.), op. cit., p. 25.

20. CAPEL MARTÍNEZ, Rosa María, op. cit., p. 157.

21. Borrador de Memoria, Archivo de la Residencia de Señoritas (Fundación José Ortega y Gasset-Gregorio Marañón).

22. Documental con motivo del Centenario de la Residencia de Estudiantes 1910-2010, realizado por la UNED del 2805-2010. Estas ideas habían sido expuesta por Teodoro de Anasagasti en 1918 en un documento que había redactado para ser presentado por la Sociedad Central de Arquitectos de Madrid al Ministerio de Instrucción Pública.

23. DIEZ-PASTOR, Concha, op. cit., p. 35

24. DIEGUEZ PATA0, Sofía, La generación del 25: primera arquitectura moderna de Madrid, Catedra, Madrid, 1997, p. 42. 25. Ídem.

26. BARTOLOMÉ COSSÍO, M., "Notas sobre construcción escolar" Discurso de ingreso en la academia de Bellas Artes de San Fernando, Madrid 1911. RODRíGUEZ MÉNDEZ, Francisco Javier, "La Institución Libre de Enseñanza y la arquitectura escolar", en Historia de la educación: Revista interuniversitaria, n. 25, Universidad de Salamanca, 2007. pp. 467-491.

27. CAPEL MARTíNEZ, Rosa María, op. cit., p. 158.

28. ZULUETA, Carmen de; MORENO, Alicia, op. cit., p. 114.

29. Memoria del edificio por Carlos Arniches, op. cit., 65/2/3, p. 3. 
Fig. 3. Alzado del mobiliario proyectado por Carlos Arniches para los dormitorios de la Residencia de Señoritas, publicado por Arquitectura.

Fig. 4. Alzado del edificio, calles Giner de los Ríos y Miguel Ángel, Carlos Arniches, publicado por Nuevas Formas 1935
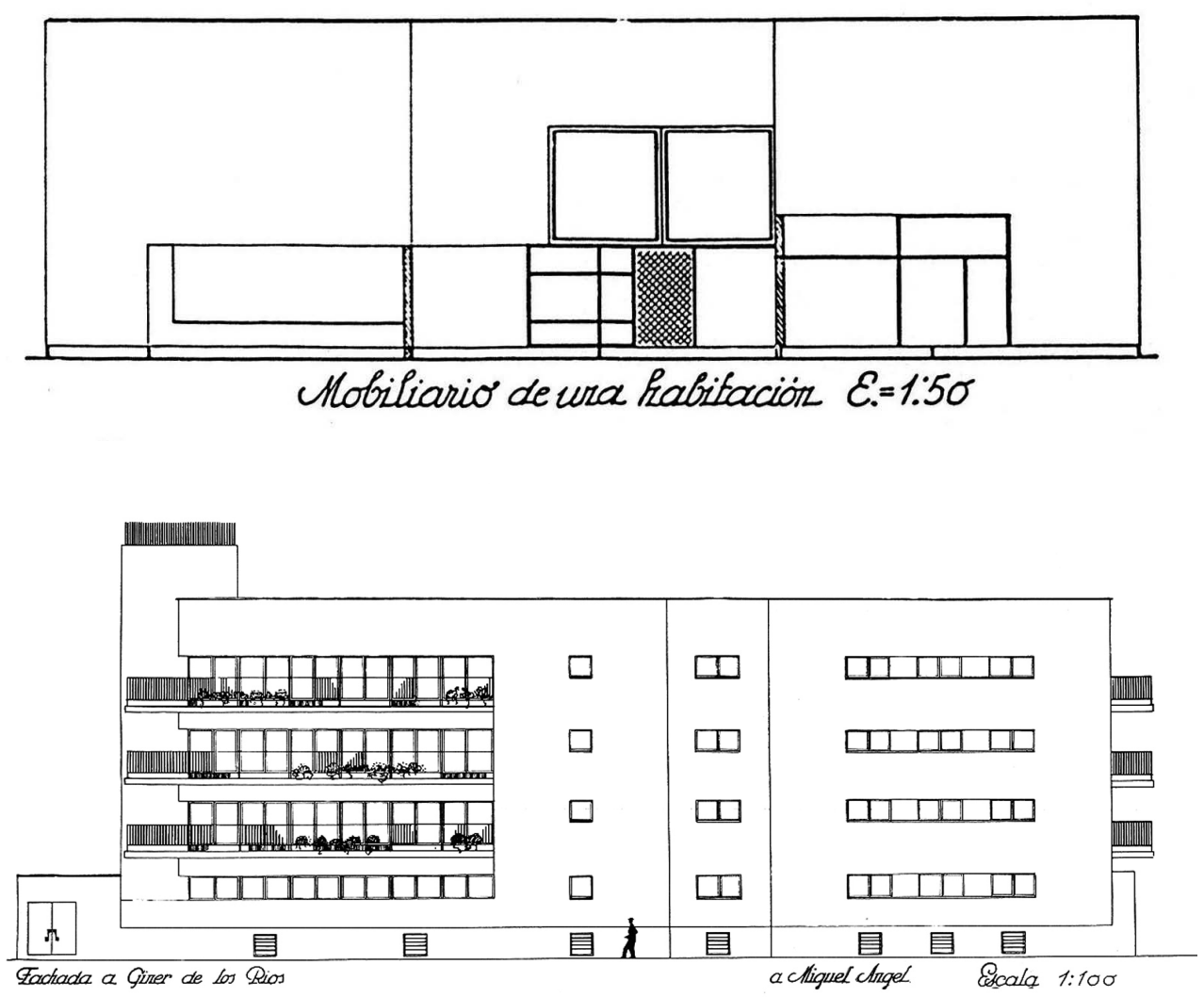

centrado un pequeño espacio de acceso a la habitación y a continuación un armario de obra ubicado en la parte central y un lavabo situado en un pequeño nicho oculto tras una cortina. Con esta solución, el arquitecto quería conseguir "una gran limpieza estética y de espacio" pues al compactar los elementos de servicio y almacenamiento se obtenía un espacio libre ordenado en un cuadrado. En total la habitación alcanzaba unas dimensiones de 3,60 por 2,90 metros.

En aquel reducido espacio las residentes debían desarrollar distintas actividades -dormir, estudiar, leer, descansar, etc.-, por lo que la distribución y el diseño de mobiliario eran fundamentales para el buen funcionamiento del dormitorio. De modo que era preciso dar respuesta a la necesidad de crear un espacio multifuncional en un habitáculo de reducidas dimensiones y, aunque Arniches ya era un arquitecto experimentado en el campo del diseño de mobiliario ${ }^{31}$, el tipo de proyecto demandado para la Residencia de Señoritas Estudiantes distaba de otros realizados con anterioridad por su ambición conceptual y pedagógica. Teniendo en cuenta todos estos factores, el arquitecto concibió un único mueble que integraba todos los elementos necesarios para desempeñar las actividades programadas en los dormitorios.

\section{EL PROYECTO DEL MUEBLE-ZÓCALO}

La pieza había sido diseñada, tal y como lo muestran los planos del arquitecto, como un plano rectangular horizontal que se plegaba y adaptaba a la forma de la propia arquitectura (Fig. 3). Se trataba de un gran zócalo que recorría la habitación perimetralmente y se adhería a los paramentos del dormitorio - al plano de fachada y a las particiones entre habitaciones- dejando libre la franja de servicios donde se encontraba el lavabo, el armario y el acceso. Su altura se ajustaba al límite inferior de la ventana de 1,80 x 0.90 metros $^{32}$ que presidía la pared de la habitación que daba el exterior, si bien en algunos puntos se desviaba unos centímetros del margen salvando el hueco de la ventana, según revelan algunas imágenes y planos.
31. Arniches y Domínguez habían diseño mobiliario para varios de sus proyectos como la Granja 'El Henar', el Bar de Hotel Palace, la vivienda particular de la calle Alfonso XII, la tienda de automóviles Ballot o la Camisería Regent.

32. Memoria del edificio por Carlos Arniches, op. cit., 65/2/3, p. 3 

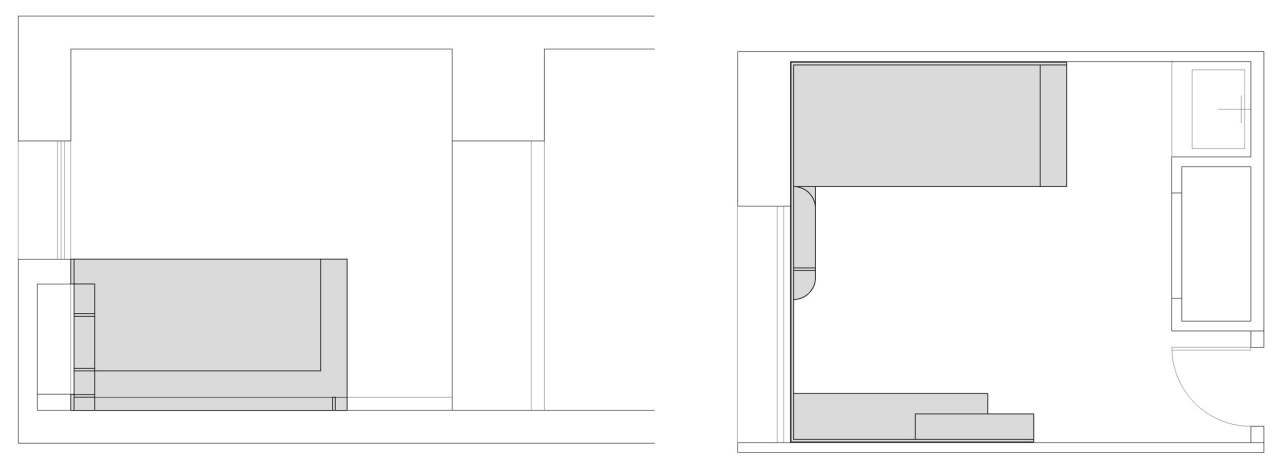

Para destacar esta característica de continuidad, Arniches representó el zócalo en un único alzado en desarrollo. Las tres caras que componen la pieza son dibujadas una seguida de la otra para potenciar la idea del arquitecto acerca del mueble único. Es especialmente llamativa la semejanza existente, tanto gráficamente como conceptualmente, entre el plano del mueble y el de fachada.

Con respecto al primer aspecto, los alzados del edificio (Fig. 4) también fueron representados como elementos continuos ${ }^{33}$. En cuanto al segundo, al igual que en las habitaciones, la Residencia presentaba en su base un gran zócalo perimetral gris oscuro, en contraposición al tono gris claro que caracterizaba el resto de la fachada, igual que ocurría en los dormitorios ${ }^{34}$.

El mobiliario había sido concebido como un único elemento -inserto en la arquitecturaque desempeñaba distintas funciones. Del zócalo emergían un armario, una estantería y una mesa para el estudio. Frente a esta pieza se encontraba un sofá-cama o diván, que contaba con dos muebles auxiliares: una pequeña estantería construida a base de planos -tres horizontales y dos verticales que los unían- y una cómoda que surgía perpendicularmente del paramento separando la cama del espacio del lavabo. El radiador también formaba parte de la composición del zócalo; ya que el arquitecto había previsto un hueco en el plano del mueble que permanecía oculto tras una rejilla.

El proyecto de amueblamiento se entendía como un único elemento contenedor de muebles que se situaba perimetralmente con la intención de liberar el espacio interior del dormitorio. Así, el zócalo ideado por Arniches envolvía el espacio y lo abrazaba de tal modo que mantenía siempre en el centro a su usuaria. El mueble creaba un espacio nuclear en el que cobraba especial importancia la residente que se alojaba en la habitación. Esta idea se pone en relación con los postulados de Giner y Cossío que, como se ha explicado anteriormente, resaltaban la relevancia del usuario en el proyecto pedagógico y de arquitectura. Además, la operación permitía organizar el espacio con un solo gesto, una "U” perimetral que contenía los elementos necesarios en la habitación (Fig. 5).

Esta solución de mueble multifuncional, diseñada por Arniches, había sido y sería aplicada por otros arquitectos durante la década de los 30 . Un buen ejemplo es la intervención en 1932 de Ginsberg y Lubetkin en el apartamento del número 25 de la Avenida Versalles de París ${ }^{35}$. Para organizar el espacio los arquitectos situaron un zócalo que contenía un diván, a cuyos lados se habían situado una pequeña cómoda y una estantería con remate semicircular, ambas dispuestas de manera perpendicular al plano de la pared. Tres años después aparecieron en las revistas otros ejemplos como los proyectos de Paul Bry y Reudenauer. El primero, proponía un mueble que contenía "tres habitaciones en una" 36 . Se trataba de un zócalo, también en "U”, que albergaba un sofá cama, una barra bajo la que se ocultaba una mesa y unas sillas y, enfrente de éstas, una pequeña cómoda del mismo tipo que las de los proyectos anteriores. El salón se transformaba en comedor -al sacar la mesa y las sillas- y en dormitorio. Esta misma idea la repite en otro espacio publicado en "Un salón dormitorio" $"$. Reudenauer ${ }^{38}$, Chareau ${ }^{39}$ y Barret ${ }^{40}$ (Fig. 6) también proyectaron un mueble similar: un zócalo que recorre tres paramentos de la habitación y que contiene librería, cómoda y un diván.
Fig. 5. Planta y sección de un dormitorio y su mobiliario. Dibujo de los autores.
33. ARNICHES, Carlos, "Nuevo Pabellón de la Residencia de Señoritas estudiantes en Madrid", en Nuevas Formas. Revista de arquitectura y decoración, 1935, n. 1, pp. 3-7.

34. Memoria del edificio por Carlos Arniches, op. cit.,, p. 7.

35. Se recomienda la bibliografía siguiente: ALLAN, J., Berthold Lubetkin. Architecture and the tradition of the progress, RIBA publications, Londres, 1992, p. 76; "Una vuelta alrededor de una habitación. Ginsberg y Lubetkin, París", en Viviendas. Revista del Hogar, 1932, n. 4, p. 22-25; "Casa de alquiler en la Avenida de Versalles, núm.25", en Obras. Revista de Construcción, 1934, n. 33, pp. 314-320.

36. Esta cita hace referencia al título del artículo dedicado a Paul Bry en la revista Viviendas. "Tres habitaciones en una. Hogar de un soltero. Arq. Paul Bry", en Viviendas. Revista del Hogar, 1935, n. 38, pp. 26-27.

37. "Un salón dormitorio. Paul Bry, decorador", Nuevas Formas. Revista de arquitectura y decoración, 1935, n. 1, pp. 50-51.

38. "Una vivienda completa en un solo cuarto. Arq. C.Reudenauer", en Nuevas Formas. Revista de arquitectura y decoración, 1935, n. 5, p. 264

39. "Interiores. Rincones de boudoirs", en Obras. Revista de Construcción, 1935, n. 40, p. 186.

40. El arquitecto M. Barret dispone un zócalo de aproximadamente 10 1,20 metros alrededor del salón. De igual modo proyecta otro zócalo para la habitación o estudio en el que incorpora el diván, de manera similar a la de Arniches. "Interiores y decoración”, en Obras. Revista de Construcción, 1935, n. 44, pp. 334-335. 
Fig. 6. Muebles-zócalo de Gisbert y Lubetkin, de Barret (arriba); de Reudenauer y de Paul Bry (abajo). En "Una vuelta alrededor de una habitación. Ginsberg y Lubetkin, París", en Viviendas. Revista del Hogar, 1932, n. 4, p. 22-25; "Un salón dormitorio. Paul Bry, decorador", Nuevas Formas. Revista de arquitectura y decoración, 1935, n. 1, pp. 50-51; "Una vivienda completa en un solo cuarto. Arq. C.Reudenauer", en Nuevas Formas. Revista de arquitectura y decoración, 1935 n. 5, p. 264; "Interiores y decoración”, en Obras. Revista de Construcción, 1935, n. 44, pp. 334-335.
41. La casa de muebles Punt Mobles que ha producido estas piezas atribuye su diseño a la pareja de arquitectos. Sin embargo, aunque la autoría corresponda a ambos, los asientos han sido denominados cada uno con el nombre de uno de Ios dos: silla Arniches y butaca Domínguez, según catálogo. 42. ZULUETA, Carmen de; MORENO, Alicia, op. cit., portada
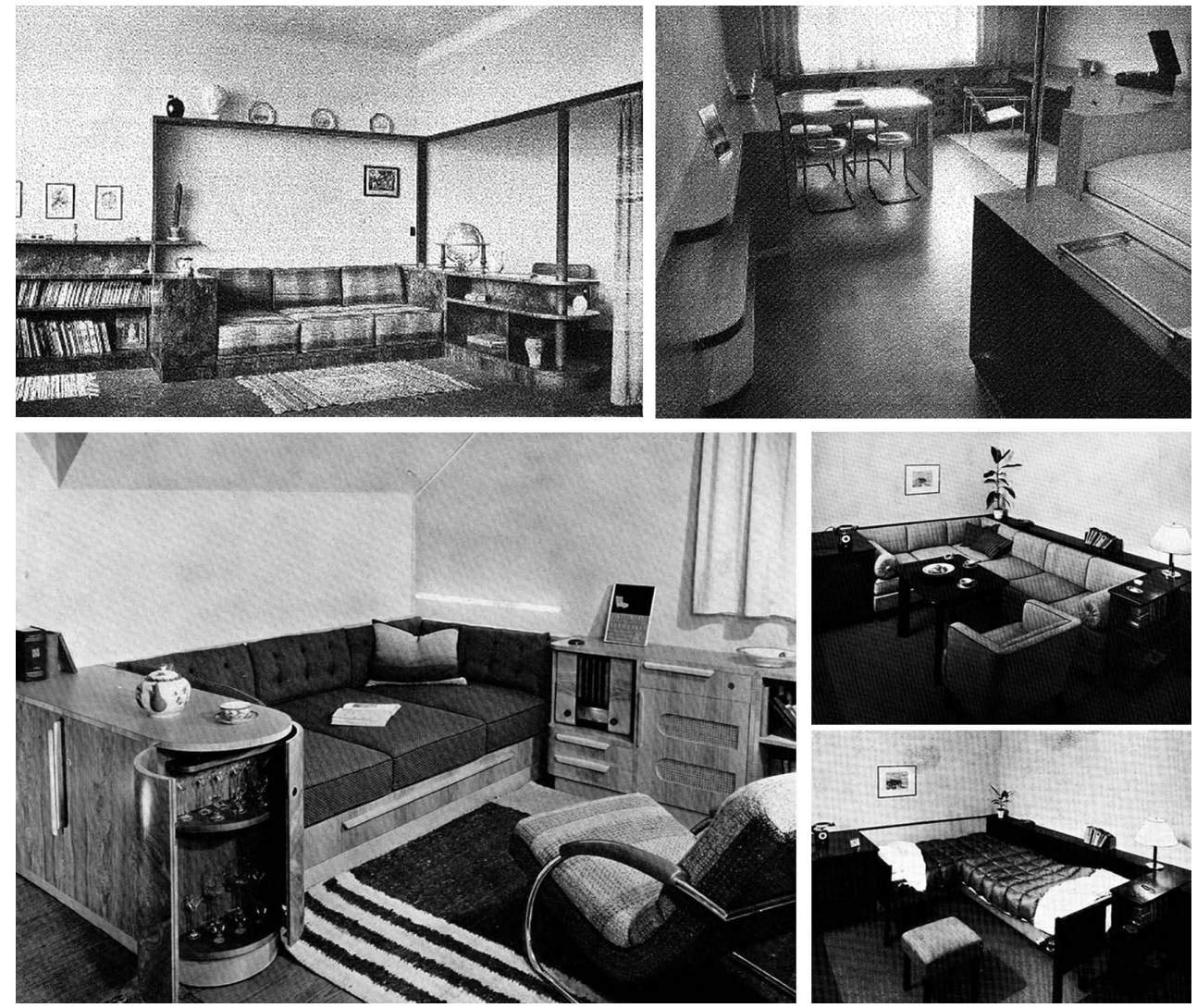

El ajuar de la habitación diseñada por Arniches estaba formado también por una silla y por un sillón de madera, ambos tapizados con una tela de tono claro. La autoría de ambas piezas es atribuida no sólo a Arniches, sino también a su compañero de trabajo Martín Domínguez ${ }^{41}$. La butaca fue diseñada en 1931 para los Albergues de Carretera y posteriormente utilizada para las habitaciones de la Residencia de Señoritas Estudiantes. Las formas simples y geométricas de la silla estaban vinculadas al reciente racionalismo, presente de forma más marcada en el edificio. El sillón había sido diseñado también en estas claves, aunque la convivencia de sus curvas y rectas desvelan la vinculación formal con modelos de estilos anteriores. Hoy en día esta pieza permanece en el edificio de la casa de Fortuny 53 (Fig. 7).

No obstante, no todas las habitaciones fueron amuebladas según el proyecto de Arniches. Algunos dormitorios - como el que refleja la fotografía de archivo elegida como imagen de portada para el libro Ni convento ni collage: La Residencia de Señoritas ${ }^{42}$ - no presentaban el mueble zócalo que recorría la pared, sino que eran equipados con distintas piezas: mesas, sillas y camas, todos ellos independientes. El ejemplo más claro de esta excepción en el amueblamiento del edificio era el de la habitación situada en el chaflán. Debido a su forma irregular, este espacio presentaba dificultades para adaptar el proyecto de Arniches, si bien algunos condicionantes económicos fueron responsables también, en parte, de esta situación.

\section{LAS EMPRESAS CONSTRUCTORAS DEL PROYECTO}

La construcción del mobiliario, así como la del propio edificio, se produjo en un breve espacio de tiempo. Sin embargo, fue un periodo de intensa actividad, en especial para la directora de la Residencia que había asumido las responsabilidades relativas a la contratación de empresas y organización de las entregas de los muebles. María de Maeztu ya había demostrado su capacidad administrativa realizando el pago de la obra del edificio con los ahorros de la propia Residencia, y ahora lo haría pidiendo y valorando los presupuestos de varias constructoras que optaban a la adjudicación de la realización de la obra. 

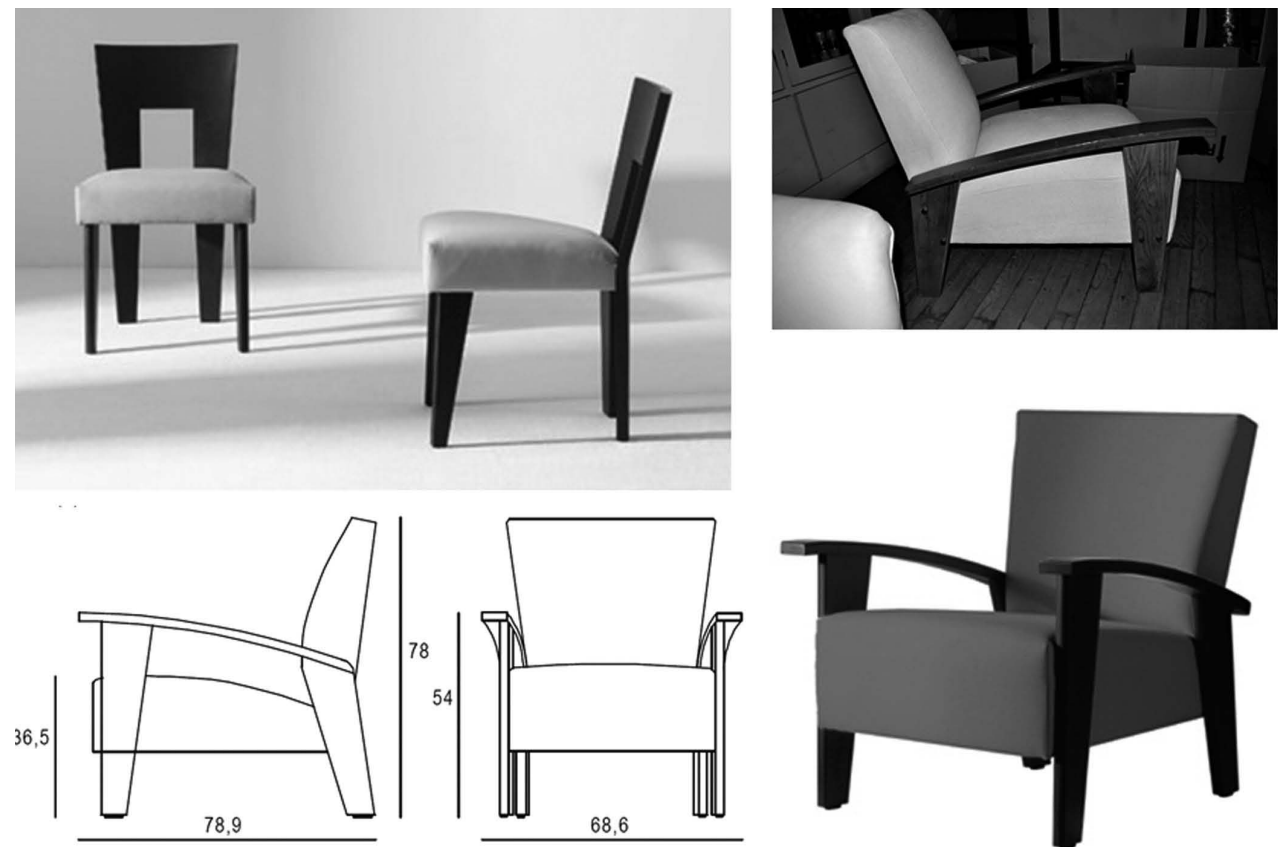

Tal y como lo había anunciado en la carta del 7 de Junio de 1932 dirigida a la Junta ${ }^{43}$, María de Maeztu había solicitado varios estudios de presupuesto para seleccionar el más conveniente. Las empresas que participaron en la convocatoria fueron José María Arrillaga, Figueroa y Valcárcel Hermanos (FIVASA) y Morales e Izquierdo ${ }^{44}$. Este último fue, finalmente, quien consiguió la adjudicación de la obra con la propuesta de presupuesto más bajo -un total de 269.406,54 ptas. Todos los datos referentes a la construcción fueron detallados en el Contrato y relación valorada de la obra ${ }^{45}$, firmado tanto por los señores Morales e Izquierdo como por Maeztu.

Sin embargo, aquel presupuesto no era suficiente para, además de sufragar la obra, cubrir el pago de la construcción del mobiliario. De hecho, desde el inicio no se había previsto incluir su coste en aquella cantidad, como así se recoge en la correspondencia dirigida a Castillejo para pedir la autorización de las obras. En aquella carta, María de Maeztu se hacía cargo de la financiación del edificio a la vez que aprovechaba la situación para solicitar a la Junta una cantidad económica para subvencionar el amueblamiento de la Residencia: "Solo esperamos que en el próximo presupuesto del año 1933 se asigne una cantidad para amoblar esta nueva casa"46.

Aquella decisión fue tomada en la sesión con la Junta del 6 de mayo de 1932. En el acta, quedaba recogida la intención de la directora de la Residencia de Señoritas de erigir un nuevo edificio, así como el siguiente punto: "8. para el mobiliario de 40 plazas nuevas en la Residencia de Señoritas, en vista del propósito de su Directora de construir con sus propios recursos un nuevo Pabellón en la esquina de Miguel Ángel y Giner de los Ríos, $25.000 " 47$.

Varios meses después, en Julio de 1933, María de Maeztu le enviaba al Secretario de la Junta una relación de presupuestos con la intención de que Castillejo los remitiera al "Ministerio de Instrucción Pública y Bellas Artes para su aprobación y en su día sean abonados por la Junta para Ampliación de Estudios con los fondos que dicho Ministerio tiene asignados para este fin" 48 .

En aquel documento aparecían los nombres de tres de las casas de la Residencia -Casa nueva de Francisco Giner, Piso Nuevo de Rafael Calvo y el Grupo de Fortuny 53- y de varias firmas de mobiliario. Según explica Concha Diez-Pastor, Arniches y Domínguez trabajaban habitualmente con Mariano Espinosa, mueblista y propietario de Lisárraga, para la realización de su mobiliario ${ }^{49}$; sin embargo, en este proyecto, al asumir tanto protagonismo el cliente, el proceso de selección de las casas de muebles se llevó a cabo de igual modo que el de la obra
Fig. 7. En la imagen superior izda., la silla Arniches; las otras tres imágenes pertenecen al sillón Domínguez. Ambas piezas han sido reproducidas por Punt Mobles. (Imagen superior dcha. realizada por los autores en la Residencia de Señoritas (FOG), el resto de imágenes en Punt Mobles).

43. Correspondencia de María de Maeztu a José Castillejo, op. cit., 65/8/1.

44. Presupuesto de José María Arrillaga, 18 de junio de 1932 Archivo de la Residencia de Señoritas (Fundación José Ortega y Gasset-Gregorio Marañón), 65/6. Presupuesto de Figueroa y Valcárcel Hermanos, 18 de junio de 1932, Archivo de la Residencia de Señoritas (Fundación José Ortega y GassetGregorio Marañón), 65/7

45. En los documentos del 28 y 30 de junio de 1932 se explicaban las condiciones del contrato, así como el coste de la obra, condiciones de pagos y plazos de ejecución. Contrato y relación valorado de la obra, 30 de Junio de 1932, Archivo de la Residencia de Señoritas (Fundación José Ortega y GassetGregorio Marañón), 65/3

46. Correspondencia de María de Maeztu a José Castillejo, op. cit., 65/8/1.

47. Documento, 7 de julio de 1933, Archivo de la Residencia de Señoritas (Fundación José Ortega y Gasset-Gregorio Marañón), 65/8/6.

48. Ídem.

49. DIEZ-PASTOR, Concha, op. cit., p. 92 (Nota al pie 215). 
Fig. 8. Presupuesto para una habitación de la firma Onrubia y Olmos, 22 de Febrero de 1933, Archivo de la Residencia de Señoritas (Fundación José Ortega y Gasset-Gregorio Marañón), 65/9/17.

Fig. 9. Presupuesto de Muebles de Arte y Estilo, 28 de Febrero de 1933, Archivo de la Residencia de Señoritas (Fundación José Ortega y Gasset-Gregorio Marañón), 65/9/22.
50. Correspondencia de María de Maeztu a Hermann Heydt, 7 de Diciembre de 1932, Archivo de la Residencia de Señoritas (Fundación José Ortega y Gasset-Gregorio Marañón), 65/9/8.

51. El 14 de febrero de 1933, Hermann Heydt envió a la Residencia un presupuesto de una habitación completa, según el modelo presentado, que ascendía a 1.300 pesetas (Presupuesto de Hermann Heydt, 14 de febrero de 1933, Archivo de la Residencia de Señoritas (Fundación José Ortega y GassetGregorio Marañón), 65/9/12.) Tan sólo dos días después la casa de muebles remitía otro desglosado de una alcoba por la cantidad 1.741,50 pesetas (Presupuesto de Hermann Heydt, 16 de febrero de 1933, Archivo de la Residencia de Señoritas (Fundación José Ortega y Gasset-Gregorio Marañón), 65/9/13).

52. En la carta de María de Maeztu a Onrubia del 27 de abril se hace referencia a este presupuesto del 22 de febrero consultado por María tras una conversación con Onrubia el día 26 de abril. En esta carta la directora de la Residencia también trata el asunto de los colchones que han de ponerse en los divanes. Correspondencia de María de Maeztu a D. J. Onrubia, 27 de Abril de 1933, Archivo de la Residencia de Señoritas (Fundación José Ortega y Gasset-Gregorio Marañón), 65/9/35.

53. Presupuesto Muebles de Arte y Estilo, 3 de Marzo de 1933, Archivo de la Residencia de Señoritas (Fundación José Ortega y Gasset-Gregorio Marañón), 65/9/25.

54. Finalmente, el 16 de mayo de 1933 acudió a la Residencia el carpintero de Onrubia y Olmos para colocar los muebles en las habitaciones modelo color negro. Sin embargo, un incidente retrasó la colocación del mobiliario, pero según la información recogida en el archivo parece ser que dos días después María de Maeztu pagó a Onrubia y Olmos una considerable cantidad del total acordado, ya que la casa de muebles había cumplido con su parte del contrato, y no era responsable de la demora. El resto, según el texto escrito a mano por María en la factura, sería abonado tras la solución del problema y la posterior ubicación del mobiliario.

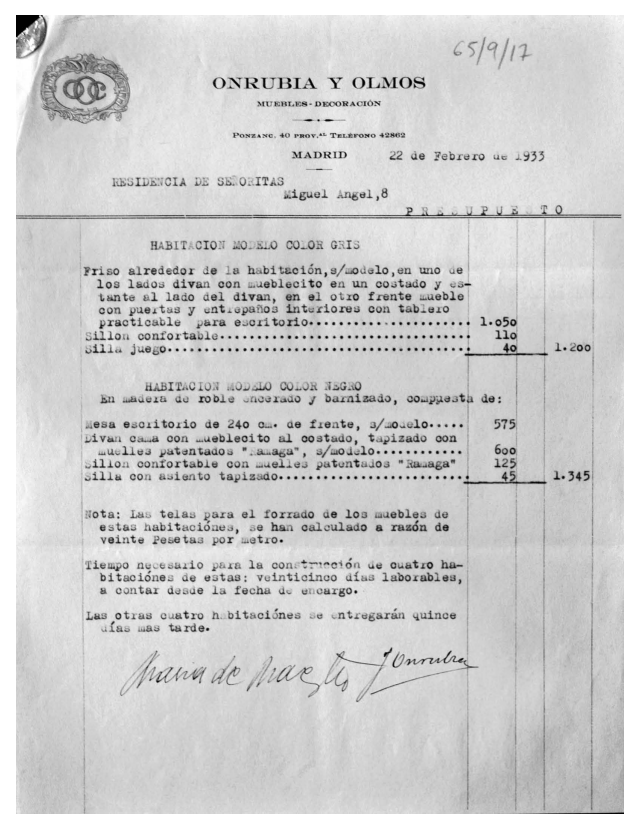

8

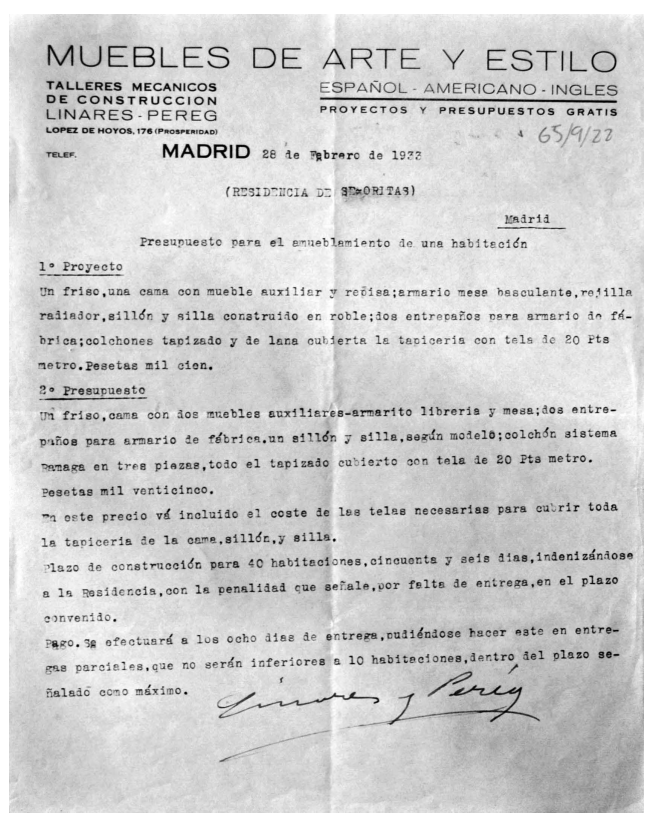

constructora. Aunque esta labor era supervisada por Carlos Arniches, María de Maeztu solicitó el presupuesto de la habitación a varias firmas de muebles, entre ellas: Hermann Heydt, Onrubia y Olmos, Casimiro Castellote, Muebles de Arte y Estilo (Linares-Pereg) y Rolaco-Mac.

Según la carta dirigida al señor Heydt el 7 de diciembre de $1932^{50}$, la empresa realizó un proyecto del que se solicitó la construcción de un prototipo como muestra ${ }^{51}$. Por otro lado, María de Maeztu encargó a Onrubia y Olmos "9 habitaciones de 1.345 ptas. cada una sirviendo de modelo la habitación color negro" " que Onrubia había visto en la Residencia, seguramente este dormitorio de muestra era el que había sido construido por Hermann He$y d t$. Por su parte, a Muebles de Arte y Estilo le fueron encargadas once habitaciones ${ }^{53}$. Por último, las nueve habitaciones ${ }^{54}$ realizadas por Onrubia y $\operatorname{Olmos}^{55}$ fueron construidas en roble barnizado y estaban compuestas cada una de ellas por: "friso, mesa escritorio, diván cama, comodita, estante, sillón, silla" ${ }^{6}$.

Por tanto, según consta en los documentos y correspondencia de la Residencia de Señoritas, las habitaciones se fueron amueblando progresivamente por tandas -nueve habitaciones de Onrubia y Olmos (Fig. 8), once de Muebles de Arte y Estilo (Fig. 9). No hay constancia entre la documentación hallada en el archivo de que se llegasen a amueblar el total de habitaciones regulares siguiendo el proyecto de Arniches. Los dormitorios situados en el chaflán fueron posiblemente amueblados también por la empresa Onrubia y Olmos, según se sugiere en la carta de María de Maeztu a Onrubia del 21 de abril ${ }^{57}$. Gracias a esta documentación -correspondencia, facturas, presupuestos- ha sido posible reconstruir, al menos en parte, el proceso de realización y ejecución de los muebles. Sin embargo, al no encontrar planos de detalle, no es factible profundizar y arrojar luz en el montaje del prototipo, uniones y medidas de cada una de las piezas que lo conforman.

Finalmente, el edificio fue inaugurado el 1 de abril de 1933, pero debido al estallido de la Guerra Civil en 1936, y tan sólo tres años después de su inauguración, el edificio fue abandonado ${ }^{58}$. Tras el conflicto bélico el nuevo pabellón sirvió de sede del Colegio Mayor de Santa Teresa de Jesús hasta su traslado a la Ciudad Universitaria. En 1985, la Residencia de Señoritas fue rehabilitada por los arquitectos Estanislao Pérez Pita y Jerónimo Junquera, que adecuaron el edificio para albergar la sede de la Fundación Ortega y Gasset - entidad que gestiona en la actualidad las propiedades de la antigua Residencia de Señoritas Estudiantes. A pesar de representar la obra de Arniches "un ejemplo de conservación" 59 , el mobiliario de las habitaciones ha desaparecido debido a este vaivén de usuarios y reformas. 


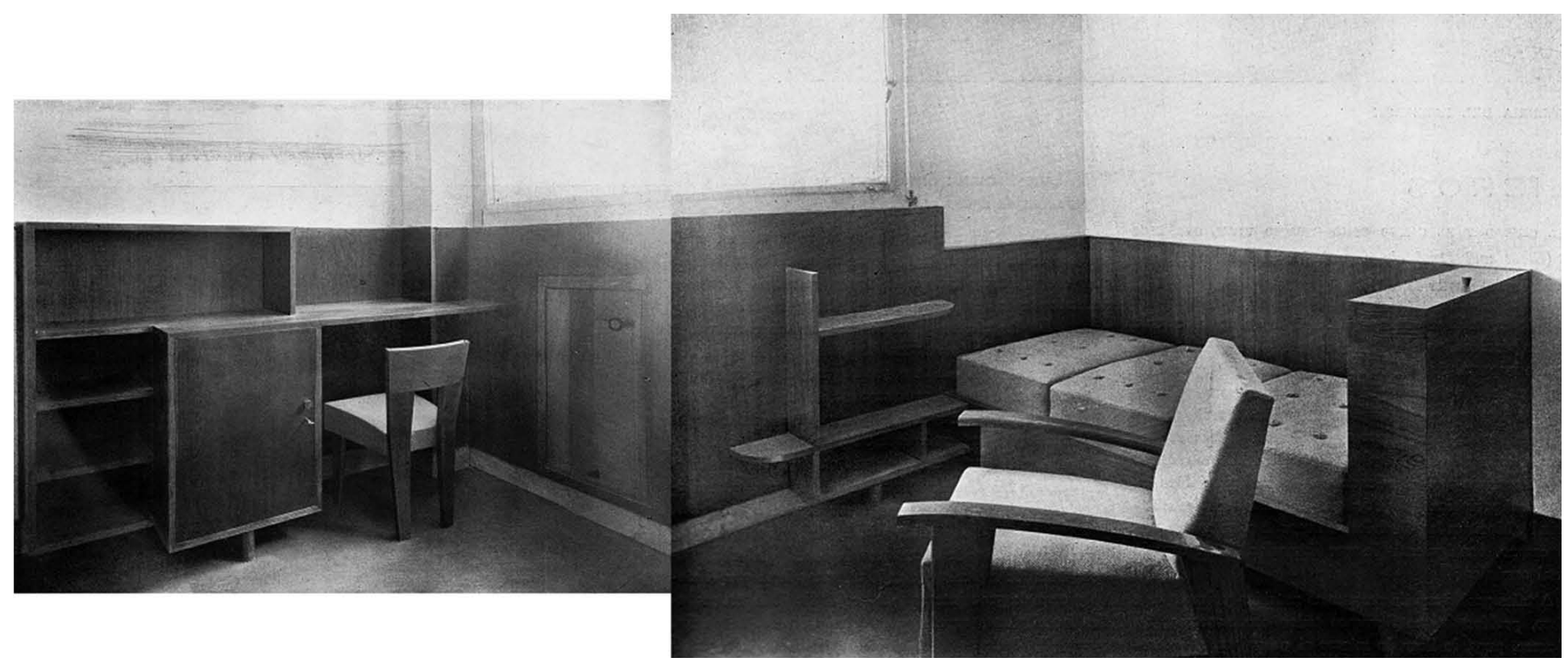

\section{ARQUITECTURA, MOBILIARIO Y PEDAGOGÍA}

La pureza compositiva del edificio y su mobiliario, carente de ornamento y eminentemente funcional, motivó que la Residencia de Señoritas de Arniches fuese un ejemplo de modernidad. Díez-Pastor definiría la obra como "la más racionalista de sus obras" Carmen de Zulueta la reconocería como un edificio "muy moderno para su tiempo" ${ }^{61}$. Oriol Bohigas llegó a definirla como una arquitectura que representaba "quizá la imagen más refinada y progresista del Madrid republicano" ${ }^{2}$, tanto por la Institución que albergaba como por la calidad de su arquitectura.

Y es que Arniches consiguió que la vanguardia del edificio se ajustase a la modernidad del proyecto pedagógico de la Institución Libre de Enseñanza. La oferta formativa, al igual que la de su homóloga masculina con la que compartía objetivos y principios, consistía en proporcionar a las residentes una formación integral. Aquella modernización y progreso en usos y patrones pedagógicos y sociológicos, buscaba proporcionar a las residentes, tomando prestadas las palabras de Virginia Woolf, 'una habitación propia' donde poder formarse intelectualmente y donde cultivarse de manera personal.

Es por eso por lo que el proyecto de Arniches se centra en el diseño integral de la habitación. Como complemento de esta arquitectura vanguardista, el mueble multifuncional completó el pabellón ${ }^{63}$, constituyendo una muestra más del austero espíritu característico de la Institución Libre de Enseñanza. La creación de un mueble cuya composición formal tenía en cuenta el espacio en el que se iba a ubicar, no sólo implicaba una voluntad estética, sino también la elaboración de una nueva tipología habitacional en la que el mobiliario y la arquitectura se complementaban (Fig. 10).

El proyecto de Arniches presentaba el mobiliario de cada habitación como un único gran mueble que desempeñaba diversos usos. Esta pieza se insertaba en la habitación y se unía a sus paramentos hasta tal punto que adoptaba y cumplía las funciones de la propia arquitectura. El mobiliario asumía el papel principal, incluso generador, del proyecto. Era un elemento organizador del espacio que desempeñaba varias funciones. Es por esto que la eliminación del mobiliario en el nuevo pabellón supone una amputación de la propia arquitectura. La extirpación del zócalo no permite hoy en día apreciar in situ la obra de Arniches tal y como fue concebida, ni comprender la voluntad del proyecto en general (Fig. 11).

No obstante, gracias a los documentos encontrados en el archivo de la Residencia de Señoritas Estudiantes, hoy ha sido posible sacar a la luz y poner en valor no sólo la mo-
Fig. 10. Fotomontaje realizado por los autores del mueblezócalo de una habitación con imágenes publicadas en la revista Arquitectura.

55. Factura de Onrubia y Olmos, 18 de mayo de 1933, Archivo de la Residencia de Señoritas (Fundación José Ortega y Gasset-Gregorio Marañón), 65/9/41. Escrito a mano por María de Maeztu especifica que el pago será realizado en dos partes: "páguese 6439'80 pts restando por pagar 5000 pts. María de Maeztu".

56. Factura de Onrubia y Olmos, 18 de mayo de 1933, Archivo de la Residencia de Señoritas (Fundación José Ortega y Gasset-Gregorio Marañón), 65/9/41.

57. Correspondencia de María de Maeztu a D. J. Onrubia, 27 de Abril de 1933, Archivo de la Residencia de Señoritas (Fundación José Ortega y Gasset-Gregorio Marañón), 65/9/35.

58. Memoria de la Junta para Ampliación de Estudios, op. cit. 59. DIEZ-PASTOR, Concha, op. cit., p. 127

60. Ibíd., p. 37.

61. ZULUETA, Carmen de; MORENO, Alicia, op. cit., p. 189.

62. BOHIGAS, Oriol. Arquitectura española de la Segunda República. Barcelona: Tusquets, 1973, p. 85.

63. GUERRERO, Salvador, "Un lugar de memoria de la geografía española de la Institución Libre de Enseñanza: Ios edificios de la Residencia de Señoritas", en DE LA CUEVA, Almudena; MÁRQUEZ PADORNO, Margarita. (Ed.), op. cit., p. 214. 

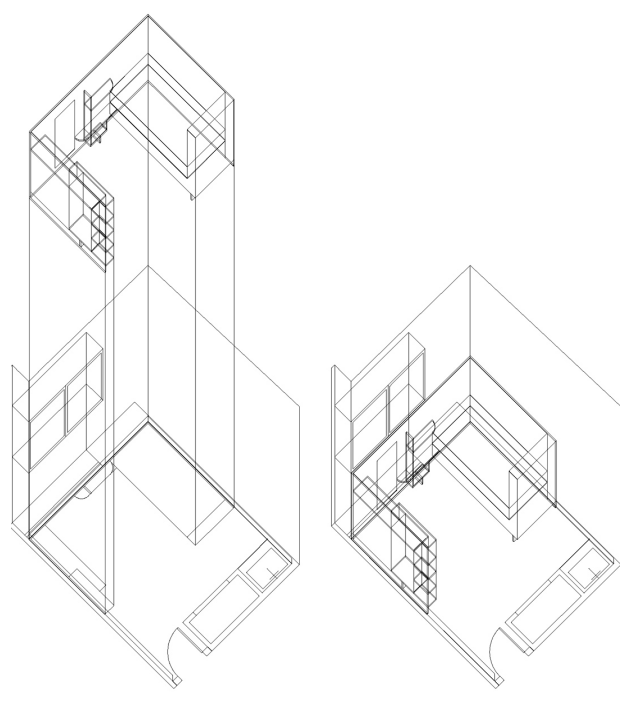

11

Fig. 11. Axonometría del dormitorio tipo y su mobiliario. Dibujo de los autores.

Fig. 12. Imagen izda., fotografía exterior de la Residencia tomada desde el jardín. Imagen dcha. fotografía de un dormitorio con el mobiliario diseñado por Arniches. Fuente: Nuevas Formas, 1935
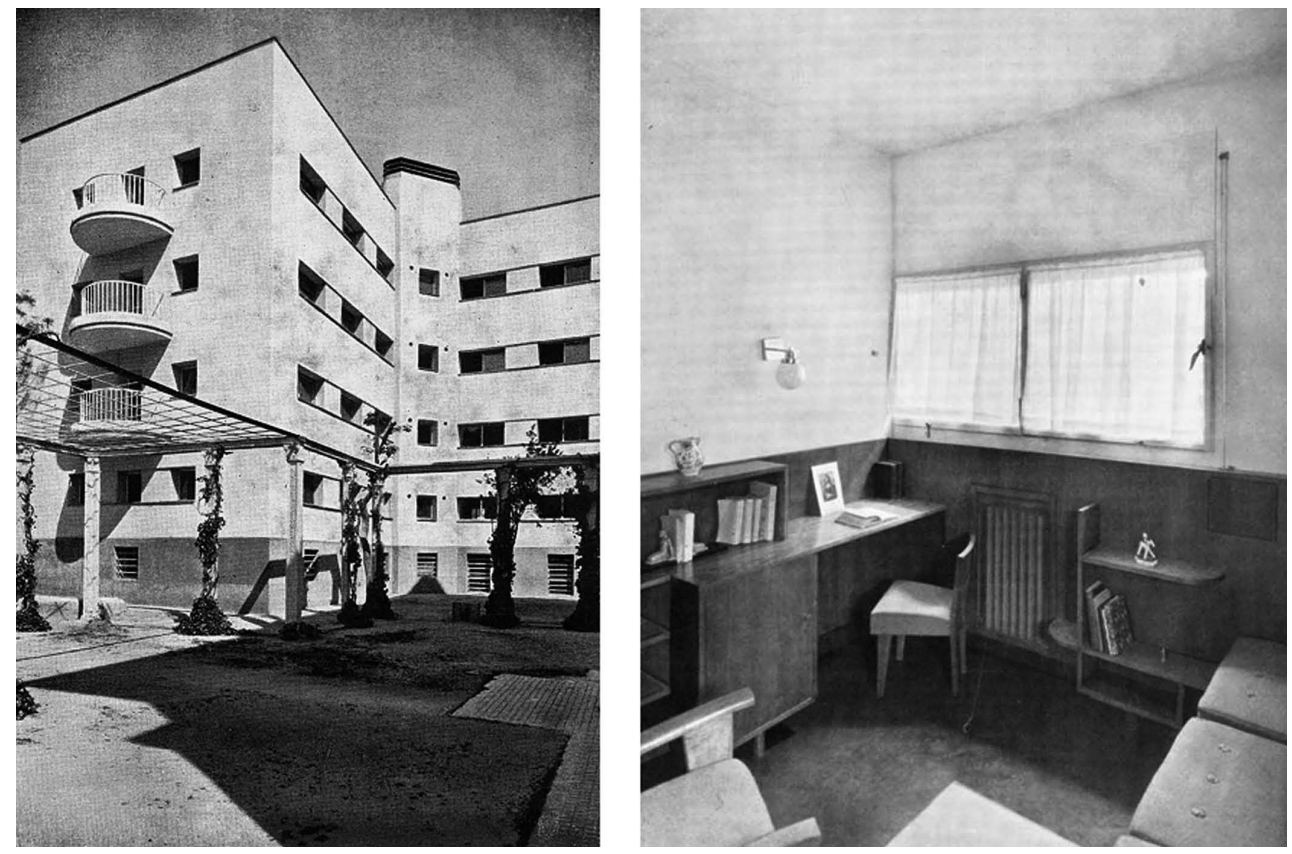

12

dernidad del proyecto de Arniches sino también su papel pedagógico en el proyecto de la Junta para Ampliación de Estudios. La colección de planos, contratos, facturas y correspondencia hallados han permitido reconstruir tanto el desarrollo formal del proyecto como la consecución de acontecimientos y protagonistas que lo hicieron posible: la Junta con José Castillejo de director, María de Maeztu, Carlos Arniches y el conjunto de empresas que colaboraron en la materialización de este sueño por la educación y formación de la sociedad española (Fig. 12).

María Villanueva Fernández. Universidad de Navarra: Dr. Arquitecto, con la Tesis Doctoral "Equipar en moderno. Mobiliario de arquitectos españoles". Premio Luis Moya Fin de Carrera. Profesora contratada doctora, desde 2008 ha estado vinculada al departamento de Proyectos de la ETSAUN y, además, ha impartido docencia en el MDA de la ETSAUN, en el Grado de Ingeniería en Diseño Industrial de Tecnun, en el MBA de ISEM y en la Facultad de Comunicación de la Universidad de Navarra. Ha realizado una estancia de investigación en The Getty Research Institute, LA y ha sido visiting scholar en la GSAPP Columbia University, NY. Los resultados de su investigación se han publicado en revistas indexadas como la revista Expresión Gráfica Arquitectónica (EGA), Proyecto, progreso, arquitectura (Ppa), Rita, revista indexada de textos académicos o Estoa.

Héctor García-Diego Villarías. Universidad de Navarra: Dr. Arquitecto, con la Tesis Doctoral "Refugio, Observatorio, Templo: Casas de arquitectos extranjeros afincados en España 1950-1975)", con Premio Extraordinario de Doctorado, Premio Extraordinario Fin de Carrera. Profesor contratado doctor, desde 2007 ha estado vinculado al departamento de Proyectos como profesor auxiliar y como ayudante doctor. En 2011, beca de The Getty Trust para estancia de investigación en The Getty Research Institute (Los Ángeles); beca por la Fundación Bancaja para investigación en la Universidad de Columbia en (Nueva York) como Visiting Scholar. Los resultados de su investigación se han publicado en revistas indexadas como la Revista Arquitectura (Ra), Proyecto, progreso, arquitectura (Ppa) o Rita, revista indexada de textos académicos, entre otras. 